\title{
BMJ Open Qualitative protocol for understanding the contribution of Australian policy in the urban planning, justice, energy and environment sectors to promoting health and health equity
}

\author{
Fran Baum, ${ }^{1}$ Toni Delany-Crowe, ${ }^{1}$ Matthew Fisher, ${ }^{1}$ Colin MacDougall, ${ }^{2}$ \\ Patrick Harris, ${ }^{3}$ Dennis McDermott, ${ }^{4}$ Dora Marinova ${ }^{5}$
}

To cite: Baum F, DelanyCrowe T, Fisher M, et al. Qualitative protocol for understanding the contribution of Australian policy in the urban planning, justice, energy and environment sectors to promoting health and health equity. BMJ Open 2018;8:e25358. doi:10.1136/ bmjopen-2018-025358

- Prepublication history for this paper is available online. To view these files, please visit the journal online (http://dx.doi. org/10.1136/bmjopen-2018025358).

Received 16 July 2018 Revised 2 September 2018 Accepted 10 September 2018

D) Check for updates

(C) Author(s) (or their employer(s)) 2018. Re-use permitted under CC BY-NC. No commercial re-use. See rights and permissions. Published by BMJ.

For numbered affiliations see end of article.

\section{Correspondence to} Dr Toni Delany-Crowe; toni.delanycrowe@flinders. edu.au

\section{ABSTRACT}

Introduction A well-established body of literature demonstrates that health and equity are strongly influenced by the consequences of governments' policy and resultant actions (or inactions) outside the health sector. Consequently, the United Nations, and its agency the WHO, have called for national leadership and wholeof-government action to understand and address the health impacts of policies in all sectors. This research responds to that call by investigating how policymaking in four sectors-urban planning, justice, energy and environment-may influence the social determinants of health and health equity (SDH/HE).

Methods and analysis The research design is informed by a critical qualitative approach. Three successive stages are included in the design. The first involves analysing all strategic policy documents and selected legislative documents from the four sectors $(n=583)$. The document analysis is based on a coding framework developed to identify alignment between the documents and the SDH/ $\mathrm{HE}$. Two policies that demonstrate good practice in regard to $\mathrm{SDH} / \mathrm{HE}$ will be selected from each sector during the second stage for embedded case study analysis (total $\mathrm{n}=8$ ). This is intended to illuminate which factors have supported recognition and action on SDH/HE in the selected policies. The third stage involves progressive theoretical integration and development to understand political and institutional facilitators and barriers to action on SDH/HE, both within and between sectors.

Ethics and dissemination The research will provide much needed evidence about how coherent whole-ofgovernment action on SDH/HE can be advanced and contribute knowledge about how health-enhancing policy activity in the four sectors may be optimised. Learnings from the research will be shared via a project advisory group, policy briefings, academic papers, conference presentations and research symposia. Ethics approval has been secured for the embedded case studies, which involve research participants.

\section{INTRODUCTION}

Life expectancies have been increasing globally over the last century. Despite some

\section{Strengths and limitations of this study}

- A census of all relevant policies will be analysed, allowing a comprehensive view of the policy landscape across and within the four sectors.

- Data collection is bounded by set time periods so will not include new documents as they are released.

- The embedded case studies focus on examples of good practice, facilitating learning about how strong policy can be developed to improve health and equity.

- The design of the study will not allow direct evaluation of the population health impacts of policy interventions, instead causal links between policy implementation and improvements in health will be theorised.

setbacks, including the HIV/AIDS crisis in Africa, people are generally living much longer than they did a century ago. The benefits of this increase in life expectancy, however, are not evenly shared, neither internationally nor within countries. ${ }^{1}$

Australia is one of the best performers. On average, life expectancy has increased by 25 years over the last century. ${ }^{2}$ In Australia, males born between 2013 and 2015 are expected to live to the age of 80.4 years and females born in this period are expected to live to 84.5 years. ${ }^{3}$ Significant gaps remain, however, between the health status of population groups in Australia based on income, education, employment status, rurality, gender and ethnicity. In particular, Aboriginal and Torres Strait Islanders have an average life expectancy approximately 10 years below the national average, ${ }^{3}$ and experience higher levels of chronic disease. ${ }^{4}$ Social changes, represented in health risks such as the obesity epidemic, ${ }^{5}$ and increasing economic 
inequities, also present new threats to Australians' health and may undermine past gains in regard to rates of morbidity and mortality, as well as population well-being overall. Given the existence of such threats, along with enduring, unfair differences in health status between population groups, a continued research focus on ways to optimise the health of Australians is vital. The Australian Research Council funded project that is outlined in this paper will contribute knowledge about how health may be improved by actions across multiple policy sectors. It builds on previous research examining action on the social determinants of health and health equity (SDH/ HE) within policies from Australian health departments only. ${ }^{6-8}$

\section{The social determinants of health and health equity}

Evidence shows that individual and population health are strongly influenced by the socioeconomic and cultural environments in which people live and work in all countries. ${ }^{19}$ It is apparent that differences in daily living conditions contribute significantly to inequalities in health outcomes within and between countries. ${ }^{10-12}$ The circumstances of daily life that influence and shape the distribution of socioeconomic and cultural resources are now widely recognised in research and policy as social determinants of health (SDH). ${ }^{13-15}$ Furthermore, health inequalities caused by avoidable and unfair socioeconomic and/or cultural inequalities are recognised as health inequities (HE) ${ }^{16}$ Effective action on $\mathrm{SDH} / \mathrm{HE}$ in policy could produce significant savings in public expenditure and improve productivity. In Australia, a study found that through such action '500 000 Australians could avoid suffering a chronic illness; 170000 extra Australians could enter the workforce,... [and] annual savings of $\$ 4$ billion in welfare support payments could be made. ${ }^{, 17}$

\section{Policy and SDH/HE}

The evidence on SDH/HE shows that health and HE can be maintained, worsened or improved by government policy actions (or inactions) both within and outside of the health sector. Effective whole-of-government action on SDH/HE relies, in part, on cross-sectoral collaboration between the public agencies responsible for different areas of government policy. ${ }^{418}$ Sustained whole-of-government action to address SDH/HE, however, remains elusive in many countries, including Australia. ${ }^{19-22}$ Furthermore, cross-sectoral strategies in Australian health policy are predominantly focused on medical care and individualised health promotion, rather than on addressing $\mathrm{SDH} /$ HE. ${ }^{8}$ As a result, it is clear that current health research requires a broader scope; allowing it to extend beyond the health sector and beyond cross-sectoral work driven by the health sector.

Adding further impetus to this research agenda, the United Nations (UN) ${ }^{13}$ and its agency the $\mathrm{WHO}^{23}$ have called for national leadership to understand and address the health effects of policies in all sectors. In 2013 an Australian Senate inquiry into Australia's national response to the WHO Commission on Social Determinants of Health ${ }^{1}$ recommended consideration of SDH/ $\mathrm{HE}$ in all relevant policy development activities. ${ }^{24}$

The research study described in this paper is responding to such calls by devising robust means to analyse how government policies in sectors other than health contribute to well-being and HE. This will be achieved through an examination of how policy and policymaking in four Australian policy sectors that do not frequently feature as partners in cross-sectoral health policies to address $\mathrm{SDH} / \mathrm{HE}^{25}$ may facilitate or obstruct action on $\mathrm{SDH} / \mathrm{HE}$. The four sectors are urban (land use) planning, justice, energy and environment.

\section{Interactions between policy areas}

There has been no systematic research in Australia to investigate how policy in the urban planning, justice, energy and environment sectors proposes action on $\mathrm{SDH} /$ HE; or how the institutional norms and values expressed in the policies of these sectors facilitate or obstruct such action. Policy settings in each of the sectors are, however, likely to have significant positive or negative effects on health and/or health inequities by affecting known $\mathrm{SDH} / \mathrm{HE}$ in many areas. These areas include incarceration, ${ }^{26}$ design of urban form and housing security, ${ }^{27}$ adaptation to climate change, ${ }^{28}$ and the shaping of the energy and employment markets. ${ }^{29}$ Policy settings in each sector may also affect $\mathrm{SDH} / \mathrm{HE}$ through interaction with those in another area; for example, housing for people exiting prison, ${ }^{26}$ or low-carbon jobs training opportunities for Aboriginal and Torres Strait Islanders. ${ }^{30}$

In each sector, policies have particular implications for Indigenous Australians' health. ${ }^{31-33}$ For example, the adverse health effects arising from the high rates of incarceration of Aboriginal and Torres Strait Islander people, occurring under justice sector policies, are likely to undermine health gains achieved elsewhere. ${ }^{31}$ Similarly, improving the health of Aboriginal and Torres Strait Islander people through work on the $\mathrm{SDH} / \mathrm{HE}$ will have flow-on effects in furthering progress towards the goals of the health sector, but also in addressing the underlying determinants of incarceration, ${ }^{26} 34{ }^{35}$ thereby reducing pressure on the criminal justice system. Acknowledging such interconnections between policy sectors, including the potential breadth of flow-on effects, highlights the importance of the current research study.

\section{Research aims}

The aims of the study are as follows:

1. Advance knowledge of the extent to which Australian federal and state/territory governments' policies in the justice, urban planning, environment and energy sectors recognise evidence and propose action on $\mathrm{SDH} / \mathrm{HE}$, in ways that are likely to improve health or reduce health inequities.

2. Identify opportunities for, and barriers to, improved action on $\mathrm{SDH} / \mathrm{HE}$ within the policy positions of the 
selected sectors, including in relation to collaboration with other sectors.

3. Advance understanding of factors leading to incorporation of actions on $\mathrm{SDH} / \mathrm{HE}$ in policy development, in each selected sector and across sectors.

4. Understand how policy in each of the selected sectors disposes them to action on social determinants to improve the health of Indigenous Australians.

5. Understand how political values and institutional norms (including those driven by neoliberalism) shaping policy in the selected sectors affect prospects for improved cross-sectoral action, or whole-of-government action, on SDH/HE in Australia.

\section{METHODS AND ANALYSIS}

\section{Assumptions informing the research design}

The design of the research is premised on the view that Australian governments can and should follow UN and WHO advice and ensure that policies in all sectors, according to their particular responsibilities, address $\mathrm{SDH} / \mathrm{HE}$ in ways that are likely to support good health, and avoid adverse effects on health. The research draws on the report and recommendations of the Commission on the Social Determinants of Health in envisaging how all four sectors can seek to ensure, as far as possible, that their policy actions create conditions conducive to health and HE. ${ }^{1}$ The research design also adopts the theoretical stance that historically accumulated political and policy values, norms and practices within government agencies (as institutions) are likely to significantly shape their dispositions (positive or negative) towards engagement in such efforts. ${ }^{36}$

\section{Critical inquiry}

Critical theory underpins the research design. The broad intent is to understand existing social systems (especially politics and bureaucracies), and examine their impacts while also assisting in the development of strategies for practical social change. The task of a critical researcher is to examine and deconstruct particular understandings of the world to show how they are produced and what the implications of their production are. ${ }^{37}$ Therefore, undertaking critical inquiry involves examining how social circumstances are mediated by dynamics of power and how they manifest within, and serve to reinforce, various inter-related sources of inequity, such as those formed on the basis of socioeconomic positioning. ${ }^{38}$ Within this approach policy is considered a key vehicle for the transmission of power. Examining policy through a critical theory lens in this research involves deconstructing the content of policy documents, interrogating the systems that produced that content and applying theory to produce new understandings. The understandings are focused on questions of what realities are produced through policy, why policies are shaped in a given way and to what effect, while reimagining how the application of different policy framings may create different, fairer, healthier social conditions.

\section{Qualitative inquiry}

A qualitative approach was selected because it facilitates the development of detailed, integrative analyses of the processes and impacts under investigation. ${ }^{39}$ Detailed analysis and explanation is vital to understand the complexity of policies and the systems that produce them. Qualitative analysis also seeks to uncover the meanings and understandings applied by policy actors directly involved in developing and implementing policy, ${ }^{39}$ which is helpful in allowing examination of their experiences and ideas.

\section{Concepts central to contemporary public health that will be explored in the research}

Two of the key concepts that have been shown to be central in contemporary public health debates-neoliberalism and lifestyle drift-will be considered during the research. This section presents an overview of the conceptual relevance of neoliberalism to the sectoral norms and values that are under examination in this study, and explains its potential to stimulate drift within policies, to which the researchers must remain attentive throughout the study.

\section{Neoliberalism as an institutional norm, and its relevance to the research}

Within public health there is a tension between structure and agency. This stems from the question of what matters more in shaping life circumstances: the influence of individual's behaviour and choices, or the influence of the social environments in which individuals live. ${ }^{40}$ The structure/agency debate has intensified with the rise of neoliberalism in contemporary societies. ${ }^{41}$ Governments influenced by neoliberal ideas (which, arguably, include all current governments in Australia) focus on facilitating competitive free markets, privatisation and reducing regulatory controls on market activity in the belief that these will stimulate individual enterprise and economic growth. ${ }^{42}$ Given this focus, there is a shift away from the belief that governments have the obligation to take responsibility for society, and to protect the well-being of individuals. This belief is being eroded during the transition towards a model where individuals are regarded as having the power and obligation to take responsibility for themselves, in the quest to become self-reliant. ${ }^{43} 44$ This stance disposes governments to favour understandings of the origins of health and ill health that focus on individualised behaviour and biomedical (rather than social) factors. ${ }^{445}$ It also encourages governments to reject their responsibility to care for citizens by creating health-promoting social and economic environments. ${ }^{46}$

During the study we explore the extent to which policy values and institutional norms in the four sectors reflect neoliberal values. If there are instances where neoliberal values are not reflected, and there instead appears to be genuine government commitment to improving the structural conditions of society in order to address $\mathrm{SDH} / \mathrm{HE}$ we examine how this has come about. Such 
investigation is useful in learning about ways governments may resist neoliberal ideals in order to pursue policies for broad social (rather than only economic) progress and well-being.

\section{Examining 'drift'}

Given the pervasive influence of neoliberalism in Australia $^{41}$ it is vital for this research to investigate whether the adoption of sociostructural or individualised views of problems and solutions are influencing policy in the four sectors in ways that facilitate or obstruct policy action on SDH/HE. Research on health policy has found that contemporary policies often make rhetorical acknowledgement of evidence on the social, economic or cultural factors affecting health, but nevertheless propose strategies predominantly focused on treating individual illness, or motivating individuals to improve health behaviours ${ }^{47-49}$; a phenomenon labelled as "lifestyle drift'. ${ }^{48}$ Theoretical perspectives on health policy suggest that such 'drift' may occur in part because of political incentives for governments in neoliberal societies to couch health problems and propose solutions in predominantly individualised terms; thereby avoiding the 'need' to contemplate politically sensitive changes to existing socioeconomic or cultural conditions that challenge powerful interests. ${ }^{50}$ Evidence supports these views, showing that governments are sometimes subject to political pressures from interest groups to frame health policy in individualised terms. ${ }^{5253}$ Our research strategy is designed to enable us to document the extent to which neoliberalism and lifestyle drift have influenced the policies and policymaking processes under investigation. Hence, as described next, we are utilising document analysis to ensure particularly careful scrutiny of the policy documents, and through this scrutiny draw out important policy silences (or vital areas not addressed in the policies) that are related to relevant aspects of $\mathrm{SDH} / \mathrm{HE}$.

\section{Design of the study}

As explained earlier the research is focused on four sectors: urban planning, justice, energy and environment. These sectors form the primary case studies for the research, as shown in figure 1.

The four sectors were selected following a rapid desktop review of departments and agencies in all Australian jurisdictions (federal and state/territory governments) to identify policy sectors with the following characteristics:

a. Sectors that are not typically regarded as health or human service sectors and which are, therefore, not usually regarded as having responsibility to promote population health and equity.

b. Sectors that nevertheless control areas of policy that evidence shows to influence $\mathrm{SDH} / \mathrm{HE}$, including in relation to Indigenous health.

c. Sectors that match the skills and experiences of the investigators.

d. Sectors that have discrete agencies responsible for the relevant areas of policy within all Australian government jurisdictions.

To provide clarity about what areas each sector covered, further desktop analysis was conducted across all governments in all jurisdictions. This resulted in us defining each sectoral area in the following ways:

- Urban planning-incorporating focus on planning, infrastructure, transport and essential services.

- Justice-incorporating focus on attorney general functions, courts, policing and corrections.

- Energy-incorporating focus on all aspects of energy systems, including generation, network management, retailing, employment, mining, resources and renewal.

- Environment-incorporating policy on environmental protection, natural resources and land management.

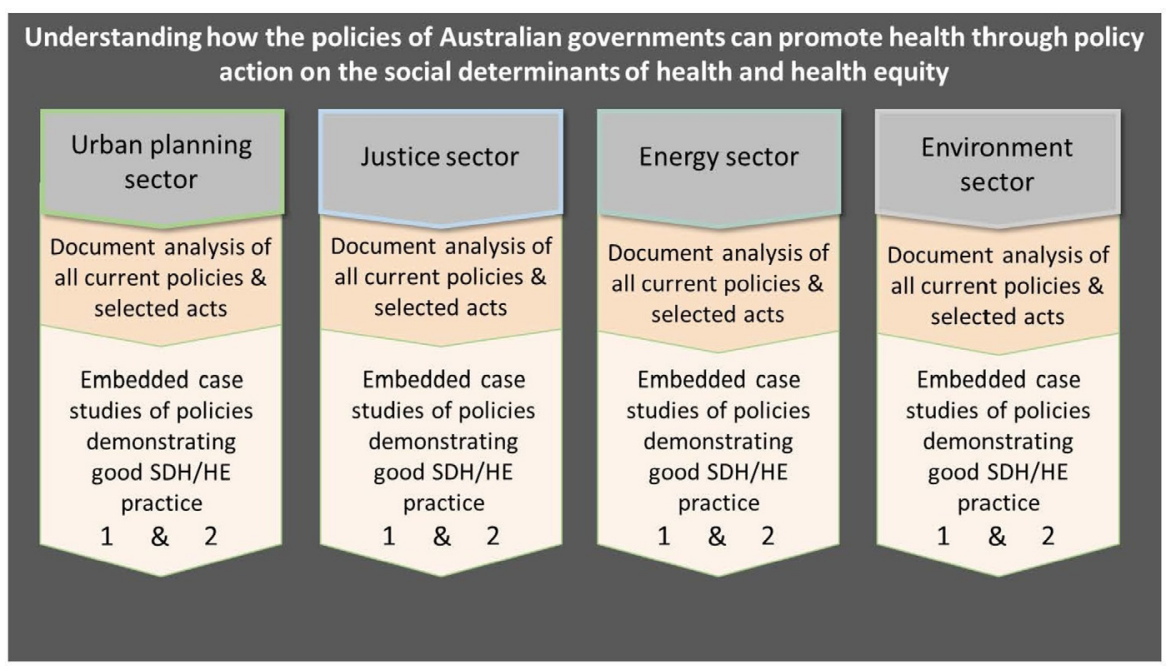

Figure 1 Overview of the research design. An overview of the research design, showing how the stage 1 document analysis leads to the stage 2 embedded case studies. SDH/HE, social determinants of health and health equity. 


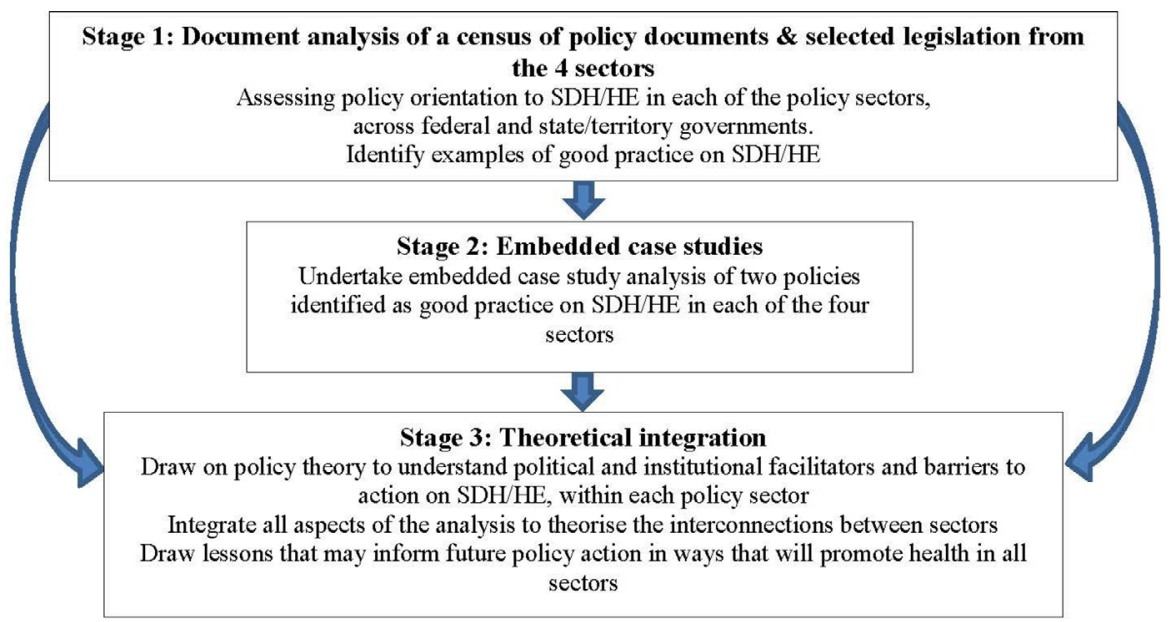

Figure 2 Successive stages of the research. Successive stages of the research, including the policy analysis, the embedded case studies and the process of theoretical integration. SDH/HE, social determinants of health and health equity.

All current policy documents from each sector have already been collected. Collecting a 'census' of policies is enabling us to sketch the landscape in each sector across each jurisdiction in Australia to understand policy activity in each of the four sectors, and to question how it is orientated to work on the SDH/HE. From the census, examples of policies that showcase good practice on $\mathrm{SDH} / \mathrm{HE}$ are being identified. Two such policies from each sector will be selected as embedded case studies. As explained by Yin, ${ }^{54}$ embedded case studies allow researchers to study multiple subunits of analysis within a broader case. The advantage of this is that researchers can focus on instances of a broader phenomenon and study those instances in detail to derive deep understandings that may not be possible from the study of an overall case as a broader whole. Analysing a case, as well as subunits of that case, allows researchers to generate a more comprehensive view, which assists in adequately addressing the 'how' and 'why' questions that drive case study research. ${ }^{54}$

Within this research, studying the embedded case studies will allow us to generate explanations about why particular policies did consider $\mathrm{SDH} / \mathrm{HE}$ and, crucially, to illuminate the conditions surrounding this inclusion. The census approach to studying each sector and the embedded case study research is being undertaken during successive stages, as shown in figure 2.

Each of the three stages shown in figure 2 is explained in detail next. At the time of writing this paper, stage 1 of the research had already commenced, and the tense changes within the paper between present and future tense reflect this.

\section{Stage 1: document analysis of a census of policy documents and selected legislation from the four sectors}

Qualitative document analysis provides a systematic procedure for reviewing and evaluating documents. Like other qualitative methods, document analysis requires data to be examined and interpreted by researchers to elicit meaning and develop understanding about what is present and not present in the data, and to what effect. $^{55} 56$ Document analysis involves coding, synthesising and theorising research data to develop empirical knowledge about a subject area. ${ }^{556}$ The first step involves collecting the necessary documents. ${ }^{57}$

Data sets of all current, strategic policy and selected legislative documents from each of the four sectors across the nine Australian governments (all state and territory governments, and the federal government) have been compiled. To be considered strategic policy, the documents needed to include the goals, objectives and strategies of a relevant department in regard to a specific area of policy responsibility. This criterion excludes documents such as operational guidelines and technical descriptions of sectoral processes. Legislation was only included in instances where it addressed an area of sectoral responsibility for which there was no strategic policy. The data collection process garnered 583 documents across the four sectors (108 from urban planning, 165 from justice, 132 from energy and 178 from environment).

The document analysis is employing a detailed coding framework and NVivo V.11 software is being used to undertake the analysis. Table 1 summarises the coding framework. During the qualitative document analysis process, each document is read at least twice by one member of the research team. The first reading familiarises the researcher with the document structure and the topics covered. The second closer reading facilitates the coding of the content of each document according to predefined categories in the coding framework (see table 1). During the coding process the framing of the document goals, objectives, strategies and values articulated throughout the document is assessed to determine how and whether these align with our adopted frameworks for understanding optimal policy action on $\mathrm{SDH} /$ HE in Australia.

Following the coding process, a document summary is written to explain whether (and if so how) the content of each policy aligns with the coding framework, to identify the main themes in the document and to highlight 
Table 1 Coding framework being applied during stage 1 of the project

Coding focus
Framing of the discussion
document content is drawn from What's the
Problem Represented to be? approach to
policy analysis. ${ }^{58}$ All introductory sections of
documents are coded to capture the perspectives
being applied by the sector. Introductory sections
are those that precede dedicated discussion
of goals, strategies and objectives in the policy
document, excluding the contents pages.

Determine the focus of the goals, objectives and strategies contained within the document.

Definitions:

Goal: Wording in the document describing what the government wishes to achieve overall (the ultimate desired outcome overall, often phrased as broad statements).

Objective: Wording in the document that describes, more specifically, a particular improvement in performance that the government intends to achieve (a more specific statement than a goal statement-it indicates what is desired for a particular aspect of activity).

Strategy: Wording describing a particular action that will be implemented within an area of government activity (ie, specific statements about what will be done).

\footnotetext{
Value statements

Value statements are coded where they are listed explicitly under sections titled 'values' or 'principles' as well as within other text where values appear more implicitly.

Values are important because how an issue is framed in a policy, and what actions are considered appropriate, depends on the values, ideas and judgements made by the people involved, those that circulate within the sector within which the policy is being written and within the broader political and bureaucratic contexts surrounding the policy (current and historical). As such values, ideas and judgements become structuring forces within policy developmenthowever, sometimes they are implicit and their role in structuring discussion is not obvious. ${ }^{68}$ Since values shape how a policy is framed it is important to determine which values are being expressed both explicitly and implicitly, to understand how and why an issue is being represented in a particular way.
}

\section{Nodes/categories}

What is the problem

represented to be? appropriate by the government?

What else needs to be addressed?

How does the sector understand the relationships between their work and health and equity?

Strength

Relates generally to health

\section{Explanation}

Text that explicitly or implicitly demonstrates what the authors of the document consider to be the problem/issue that needs to be addressed by the particular policy document or Act that is being coded.

Text that highlights what the government thinks is necessary to address the problem/issue identified above, that is, what is the policy/Act designed to do?

Text that highlights what else the government considers to be problematic, even though these problems/issues may be outside the scope of the particular policy/Act being coded.

Text that highlights explicitly or implicitly how the authors of the document understand the connections between the work of their sector and the health and/or equity of the population.

What is identified by the government as an existing strength in the policy area.

All goal/objective/strategy statements that are consistent with a general focus on health but that do not mention a specific SDH from the list shown in box 1.

Relates to a specific SDH

All goal/objective/strategy statements that include reference to a specific SDH from the list shown in box 1.

Relates to equity

All goal/objective/strategy statements that are consistent with a focus on narrowing avoidable and unfair gaps between groups (a levelling up approach to equity), or on making improvements across the gradient of advantage/disadvantage (a gradient approach to equity).

Other

Other goal/objective/strategy statements that are not related to health, equity or $\mathrm{SDH}$.

Relates generally to health

Value statement that reflects the importance of health in general.

Relates to a specific SDH

Value statement that reflects the importance of a specific SDH listed in box 1.

Relates to equity

Value statements that reflect the importance of equity or fairness.

Other Other value statement that is not related to health, equity or an SDH. 
Table 1 Continued

Coding focus
Evidence use to support claims
Evidence use is determined through analysis of
there being citations included in the documents.
Instances in the document that explicitly refer to
evidence use without a citation are also coded-
such as 'Evidence suggests that ...'
In addition, where the title of a document is
included in a sentence but no formal citation is
included, this is still coded as evidence.
Exclusions: Sweeping statements such as 'It is
well known that...' are not coded as reflecting
evidence use if no formal citation or document
reference is provided to support such sweeping
statements.

\section{Policy intent}

Involves an assessment of policy intent drawing on Margaret Whitehead's typology ${ }^{60}$
Nodes/categories
Explanation
Evidence-health
Evidence-SDH
Evidence-equity
The citation/evidence reflects an explicit focus on health.
The citation/evidence appears to reflect a focus on one of the SDH in box 1.
The citation/evidence reflects a focus on equity (levelling up approach or gradient focus).

Other evidence-not related to health, equity or SDH
Evidence is cited/referred to in the document but does not appear relevant to the focus of this research.

\section{Strengthen individuals}

Strengthen communities

Improve living and working conditions

Address socioeconomic inequities
Statements that reflect the aim of strengthening individuals, using individually focused strategies.

Statements that reflect the aim of strengthening communities through building social cohesion, capacity within communities and mutual support between community members.

Statements that reflect the aim of changing the broader social and environmental conditions that people live and work in. This includes both social and physical environments, as well as the economic, cultural and political influences that shape those environments.

Statements that reflect an explicit intent to directly change the distribution of resources - rather than to provide once off alms or reactive band-aid solutions.

\section{Collaboration}

Includes references to the importance of

Collaboration-intersectoral

intersectoral, private sector or community collaboration.

References to the importance of collaborating within and across the departments/sectors of governments. Also includes statements about the importance of the different levels of government working together.

Collaboration-private sector References to the importance of collaborating with involvement

Collaboration-community involvement

$\begin{array}{ll}\text { Explicit references to key groups and concepts } & \text { Mention of-Aboriginal } \\ \text { within the documents } & \text { Australians or Torres Straight } \\ \text { Islanders } & \text { Mention of -health word }\end{array}$

Mentions of other related documents

Policy document

Act

Other related document private sector organisations.

References to the importance of involving/ consulting with the community as a whole or subgroups within the community.
Any sentence where an explicit reference to

Aboriginal Australians or Torres Straight Islanders appears is coded.

Any sentence where the following word/s is mentioned:

health, well-being, fitness, fit, illness, disease, wellness, equity, inequity, equality, inequality is coded.

All references to other policies are coded.

All references to other Acts/legislation are coded.

All references to related documents that are mentioned in the policy/Act are coded (eg, guides/ handbooks, etc).

$\mathrm{SDH}$, social determinants of health.

the dominant focus being applied (eg, a neoliberal focus on economic gains, a focus on structural change, or an emphasis on the need to modify the behaviours of individuals, etc). After all documents in a jurisdiction (federal, state/territory) have been coded for each sector, a jurisdiction summary is then written, highlighting the 
key themes and policy intent across the jurisdiction. In both the document and jurisdiction summaries silences are identified where no aspect of the document can be coded into a particular category within the framework. Additionally, silences are being identified when the strategic intent of the objectives and/or proposed strategies of the document do not align with the stated goals, leaving some aspects either completely or partially ignored within the proposed actions. It is at this stage that lifestyle drift is being identified through reflection on instances within policy documents where the goals of the policy recognise or express an apparent intent to address $\mathrm{SDH} / \mathrm{HE}$, but this is not followed through in the proposed strategies, with an emphasis instead on strategies to change individual behaviour.

The coding results and document summaries are peer reviewed during research team meetings. The team meetings are held fortnightly, and are conducted on a sectorbased rotation, so that each sector is discussed among the investigators and project staff at least once every 2 months. Periodically a meeting on all sectors is held to discuss the intersections between the findings that are emerging across the sectors.

During team discussions, the analytical approach of Bacchi $^{5859}$ is being applied to question how the framing of the documents may influence policy development and implementation, and how responses to defined problems would differ if the intent and goals articulated in the documents were framed differently. In addition, Whitehead's ${ }^{60}$ typology of actions is also being used to examine the theory of change that underlies the intent of each policy (ie, questioning if the intent is to strengthen

\section{Box 1 Social determinants of health}

Segments of text are coded as referring to a social determinant when they reflect a focus on any of the following:

- Education. ${ }^{16970}$

- Food. ${ }^{6971}$

- Health systems. ${ }^{169}$

- Housing (excludes prisons). ${ }^{6972}$

- Distribution of income. ${ }^{1}$

- Stigma/discrimination (based on race/ethnicity or other characteristics). ${ }^{72}$

- Social relationships. ${ }^{169}$

- Social exclusion. ${ }^{72}$

- Transport. $^{71}$

- Employment. ${ }^{172}$

- Welfare system. ${ }^{72}$

- Land/country. ${ }^{72}$

- Gender. ${ }^{1}$

- Safety. ${ }^{73}$

- Culture. $^{72}$

Open space.

- Natural environment. ${ }^{28}$

- Built environment. ${ }^{74}$

- Climate change. ${ }^{28}$ individuals, strengthen communities, improve living and working conditions or address socioeconomic inequities).

\section{Stage 2: embedded case studies}

The coding process will identify examples of policies that demonstrate good practice in addressing $\mathrm{SDH} / \mathrm{HE}$. Two such policies will be selected in each of the four selected sectors $(n=8)$ as embedded case studies. The aim is to understand in greater depth the factors that enable consideration of SDH/HE during policy development and to assess whether implementation of the selected policies is inclusive of efforts that will progress $\mathrm{SDH} / \mathrm{HE}$. The embedded case studies will be framed by a critical realist evaluation approach.

Critical realist evaluation will allow us to engage beyond the question of whether a policy proposes work on the $\mathrm{SDH} / \mathrm{HE}$. We will examine why specific policies have incorporated $\mathrm{SDH} / \mathrm{HE}$, what circumstances and conditions made this possible and how work on $\mathrm{SDH} / \mathrm{HE}$ is being progressed during policy implementation. ${ }^{40}$ If work on SDH/HE has not formed part of the implementation focus, we will examine what has impeded this, ${ }^{61}$ and question which institutional norms and factors, such as neoliberal values and lifestyle drift, have had an impact. Consistent with the broader aims of the study, selection of policies for the embedded case studies will include at least three policies that specifically address the health of Aboriginal and Torres Strait Islanders.

The embedded case study research will involve analysis of documents associated with each selected policy as well as key policy actor interviews. The interviews will be focused on examining the factors that enabled $\mathrm{SDH} / \mathrm{HE}$ to get onto each sector's policy agenda, and on exploring whether implementation has incorporated actions that are likely to progress $\mathrm{SDH} / \mathrm{HE}$. The interview schedule will be informed by the work of Kingdon, ${ }^{62}$ Lewis ${ }^{63}$ Bacchi ${ }^{59}$ and Hall. ${ }^{64}$ As such, the interviews are intended to elicit interviewees' views on the various institutional, political or conceptual factors, and use of evidence, which influenced the focus and content of the policies, as well as their implementation. Interviewees' views on whether an individualised or social/structural perspective was adopted to define the problem/s to be addressed, or to shape the preferred policy 'solution' to be applied during policy development and implementation, will also be collected during the interviews.

The processes for interviewee recruitment and case study data analysis are as follows. Senior executives within the departments that developed each selected policy will be consulted to identify a key contact person, who will be asked to assist with identifying a policy network for each case study. ${ }^{63}$ Further key actors will be identified by snowball sampling as the embedded case studies progress. ${ }^{39} 55$ Between 8 and 12 key actors will be interviewed about each of the eight selected policies. They will be individuals who hold, or held at a relevant time, a senior position and have direct experience of the policy's development and/ or implementation. This may include departmental staff, 
ministers or ministerial staff and advisors from outside government. The policy actors (including politicians, public servants and civil society activists) will be asked to engage in a 1-hour semistructured interview to explore their perspectives on the development and/or implementation of the policy, and to identify any documents that illuminate the political/policy context in which the policy has been developed and implemented. Data from the interviews and documents informing the case will be analysed (assisted by NVivo V.11) with a coding structure designed to identify how specification of a policy problem, selection of policy options, political and institutional context, and recognition of evidence influenced the content of the policy, and specifically its consideration of SDH/HE during both policy development and implementation. A detailed interrogation of how the policy actors view the issue of lifestyle drift and the impact of neoliberalism on contemporary policy contexts will also form part of the analysis process.

\section{Stage 3: theoretical integration}

During stage 3 social and political science theories will be used to illuminate the operation and implications of the problem definition processes ${ }^{59}$ political interests ${ }^{62}$ and institutional values and norms (including neoliberalism) ${ }^{6465}$ that are identified during stages 1 and 2. This will assist in identifying the political and institutional factors that facilitate, and present barriers to, action on $\mathrm{SDH} / \mathrm{HE}$ within and between the selected sectors. With stage 1 data, application of theory will assist in understanding whether or not each sector's policies, as a group, feature particular characteristic values, goals and/or problem conceptions, and in understanding how these may have delimited the objectives and strategies in ways which are favourable or unfavourable to action on SDH/ HE. Application of theory to stage 2 data will facilitate understanding about how policy development processes (involving ideas, structures and actors) are influenced by political and/or institutional factors, including tacit or explicit theories of the nature and causes of the policy problem to be addressed, and how this can best be achieved. Stage 3 will draw all the findings together, with a focus on understanding the themes that emerge consistently across all the four sectors, illuminating the various interconnections.

\section{Research governance}

As alluded to previously, the research is being undertaken by a team of researchers with a track record of working together, and within the sectors that have been selected as the primary case studies for this research. The chief investigators are a collaborative group of multidisciplinary researchers led by a public health social science researcher (FB) and comprising expertise in political philosophy (MF), Indigenous health (DMcD), urban planning and public health $(\mathrm{PH})$, healthy public policy $(\mathrm{CM})$ and economics, political economy and sustainability (DM). Partner investigators bring expertise in the areas of urban planning, public health policy, justice sector structure, processes and impacts, bureaucratic governance, intersectoral collaboration and environmental sustainability.

Continuing regular meetings between the members of the research team throughout the study will be vital. The meetings include discussion of findings from the coding and also discussion of broader theoretical meaning. The project manager (TDC) is coordinating the meetings and the data collection and analysis processes.

To avoid the emergence of group-think within the project team, and to provide valuable sectoral insights and encourage policy relevance and translation, a Project Policy Advisory Group (PPAG) has been formed. Invitees to this group have direct policy-related knowledge and experience from the sectors being examined in this study. The group includes senior public servants from a number of jurisdictions, non-government organisations and academic institutions with a record of interest in public policy action on $\mathrm{SDH} / \mathrm{HE}$. It is envisaged that the PPAG will meet every 6 months over the course of the project, and advise the research team on issues in the policy environment related to the research aims, as well as support dissemination of outputs. The research team will use the PPAG meetings to test the relevance and usefulness of the findings. A combination of informal dialogue, formal meetings, written policy briefings and organised policy symposia will also be used throughout all stages of the research to gain broader feedback and input on the meaning of the emerging findings.

The intersectoral discussions that occur during the PPAG meetings, as well as the collective team meetings, will be essential in highlighting the interconnections between sectors and policy impacts, to ensure that each sector is not studied as a siloed entity. Interrogation of the interconnections between sectors will facilitate broader theorisation of the meaning and relevance of the findings during stage 3 of the research.

\section{Patient and public involvement}

Due to the nature of the research, patients were not involved in the design of this study. However, findings will be disseminated to all study participants as described next.

\section{Ethics and dissemination}

The research will provide policy-ready evidence on good practices on $\mathrm{SDH} / \mathrm{HE}$ that is relevant to multiple sectors. Such evidence may be useful in influencing current policy development and implementation practices, increasing the likelihood that future policies will be more coherent, forming part of a whole-of-government approach to reduce adverse health impacts, promote well-being and achieve beneficial flow-on effects in all sectors. A range of dissemination strategies will be used to ensure that learnings can be shared effectively with academic and policy audiences. These will include the regular sharing of findings during the PPAG meetings, the release of policy briefings to all jurisdictions (including direct 
dissemination to all interview participants) and the publication of academic papers and conference presentations. An initial research symposium has already been held to share research plans and background information on this area. Another symposium will be held at the conclusion of the project to share findings. Ethics approval has already been secured to allow the embedded case study research to proceed. However, once policies from the justice sector have been selected, additional ethics clearance may be required to allow interviewing of departmental staff.

\section{Practical and operational issues}

The focus on four sectors means that the research is inherently interdisciplinary. While this is a strength of the design, achieving true interdisciplinarity requires the researchers to deal with practical issues. For example, the researchers will need to review, understand and apply perspectives from the urban planning, justice, energy and environment sectors as well as from the field of public health. Journal publishing word limits, as well as the scope and disciplinary boundaries of journals, will make this task difficult. To overcome these issues, it is likely that publication efforts will be aimed at carefully selected journals with the appropriate scope and disciplinary focus. We plan to combine overviews of all findings with papers dealing more deeply with literature and research findings from each sector. Furthermore, the interdisciplinary research focus will require the researchers to engage with all policy departments that are connected to the four sectors across all nine jurisdictions of government (federal as well as all state/territory governments in Australia).

Forming strong connections with policy actors on the PPAG will be central to this. However, not all departments are represented on the PPAG, so the researchers will need to devise strategies for connecting with the broader policy network in ways that satisfy the requirements of truly collaborative research, but that also ensure efficiency. One strategy will be forming relationships with policy staff in some relevant departments during the embedded case studies. Contact with a broader policy network will also be ensured by the researchers consulting all relevant departments to seek feedback on the findings of stage 1 via the policy briefings, and by inviting staff from all relevant departments to research forums that will be livestreamed to encourage broad geographical participation.

The research also involves considerable conceptual complexity. Complexity is associated, in particular, with the relevance of critiquing pervasive, dominant social ideologies that shape current norms and influence the subsequent definition of policy problems and appropriate responses. Articulating neoliberalism will not be easy because its influence on policy is likely to be far reaching and not always be easily detectable in individual policy documents. The research team will establish and reflect on coding processes to understand the nuances and impacts of institutional factors, including neoliberalism. Thus, researchers will record their reflections in the document and jurisdiction summaries during stage 1 to broaden focus from the specific coding categories to thinking about the ideological orientations of each document, how policy problems are being framed and what the dominant focus in each document/sector is. Research team meetings include critical discussions about the ideological underpinning of the key findings that are emerging, allowing discussion about the relationships between key themes and the broader ideologies that permeate thinking and action in each sector and jurisdiction.

Detecting lifestyle drift will be facilitated by the researchers comparing the goals, objectives and strategies articulated in each document, to determine the extent to which broad statements of intent to tackle $\mathrm{SDH} / \mathrm{E}$ are either implemented, or instead diverted into actions focused on changing the behaviours of individuals.

Researchers will be attentive to the concept of policy silences. The coding process will identify what content exists within the policies, and stimulate thinking about alternative problem definitions and unaddressed aspects of policy topics. Examining silences will render visible how neoliberalism and lifestyle drift may be pushing policy in particular directions, while keeping alternative problem definitions off the policy agenda.

Importantly, advocates for healthy public policy have called for cross-sectoral action to harness the opportunities that arise from greater understanding of how interconnections between policy areas affect health and equity. Yet as alluded to earlier, most intersectoral action has been limited to extending health sector medical and behavioural programmes into other social policy sectors. ${ }^{25}$ This can intensify a narrow focus on individuals rather than populations, and avoid interventions designed to tackle SDH/HE. For example, cross-sectoral collaboration between the justice and health sectors has been shown to be limited to prisoner assessment and improving access to remedial healthcare for people already in prison. ${ }^{25}$ The focus on assessment and healthcare for prisoners, while important, is unlikely to prevent incarceration or to address the underlying social, cultural and economic factors that perpetuate the cycle of incarceration. This research will, therefore, focus on making clear how policies in our selected sectors can, in their own right, act to both promote health and prevent threats to health thus tackling the social determinants at their roots. Our publications will engage with theory and use the advice of policymakers to recommend how our case study sectors could form partnerships with the health sector that do address the roots of SDH/HE and avoid lifestyle drift.

Ensuring rigour during the coding process is vital, particularly in light of the challenges associated with the project, such as the conceptual complexity of the research focus, the large number of policy documents and the need to distribute coding tasks between multiple researchers. Strategies to ensure rigour will include collaborative coding of policy documents to check consistency of approach, regular discussion of coding summaries to 
ensure appropriate depth of analysis and regular meetings between coders to discuss areas of uncertainty and to develop mutually agreed solutions to coding difficulties. A detailed coding guide has already been developed by the research team and is in use. This guide directs the coders to follow a consistent approach to the analysis and reminds them of the areas they need to be attentive to. Importantly the guide defines the concepts used in the coding framework. The application of consistent understandings during the coding process is imperative to achieving a consistent and transparent analytical focus.

\section{Limitations of the research}

While this research is important, and necessarily ambitious, some limitations are evident. As explained earlier, a strength of the research is that a census of all relevant policies will be included in the study. This will allow us to develop a comprehensive view of the policy landscape across and within the four sectors. Given that the policy landscape is so dynamic (reflecting its political roots), we are conscious that the landscape will be changing even as we conduct the research. Because data collection is bounded by set time periods we will not be able to include new documents as they are released, or as political events change policy direction. However, to ensure that the policy analysis is rigorous, and remains manageable, it is vital that we apply transparent, time-bound criteria for document collection. This demonstrates, in action, the clash between the research world (in which detailed analysis takes time) and the policy world (which changes rapidly in the face of bureaucratic and political flux).

The four sectors will be studied within a federated system. Australia has three levels of government: federal, state and territory, and local. Our focus is on policies from the first two levels. Local government has been excluded to ensure that the project scope remains manageable.

Furthermore, the design of the study will not allow direct evaluation of the population health impacts of policy interventions. Instead, our ability to theorise causal links between policy implementation and improvements in $\mathrm{SDH} / \mathrm{HE}$ will be based on our analysis of published literature.

\section{Summary of the research significance}

This research will develop and test a protocol that can be applied across all policy sectors to understand the potential impact of their proposed actions on SDH/HE. The research findings that are produced through this study will enhance Australia's knowledge base and research capability in understanding the crucial and complex intersections between public policy (divided into policy sectors carrying out different functions) and work to progress the $\mathrm{SDH} / \mathrm{HE}$. This is important since optimised, systemic action on $\mathrm{SDH} / \mathrm{HE}$ has significant potential to reduce public spending in a number of policy sectors, as well as to contribute to improved economic productivity and disease prevention. ${ }^{17}$
There has been significant, recent recognition in Australia's federal parliament of a need for more coherent action on SDH/HE across policy sectors and levels of government ${ }^{24}$; including specifically in relation to Aboriginal and Torres Strait Islander health. ${ }^{1466}$ This research will provide evidence to policymakers about opportunities to improve the engagement of all policy sectors in ways that have the potential to reduce health costs and contribute to closing the health gap between Indigenous and non-Indigenous Australians. Overall, the research will provide much needed evidence on concrete ways in which coherent whole-of-government action on $\mathrm{SDH} / \mathrm{HE}$ can be advanced in Australia to enhance wellbeing and address health inequities. ${ }^{67}$

\section{Author affiliations}

${ }^{1}$ Southgate Institute for Health, Society and Equity, Flinders University, Adelaide, South Australia, Australia

${ }^{2}$ College of Medicine and Public Health, Flinders University, Adelaide, South Australia ${ }^{3}$ Menzies Centre for Health Policy, University of Sydney, Sydney, New South Wales, Australia

${ }^{4}$ Poche Centre for Indigenous Health and Wellbeing, Flinders University, Adelaide, South Australia, Australia

${ }^{5}$ Sustainability Policy Institute, Curtin University, Perth, Western Australia, Australia

Acknowledgements Professor Margaret Whitehead, Professor Peter Sainsbury, Ms Carmel Williams, Dr Anthea Krieg and Associate Professor Lester Wright are partner investigators on the research project. All have advised on the research design, guided the conduct of the research and contributed sectoral-based expertise. $\mathrm{Dr}$ Michael McGreevy and Ms Emily Riley are employed as researchers on this project, and have key roles in data collection and analysis. Dr Michael McGreevy provided research assistance to support the development of an early draft of this manuscript by reorganising and reformatting the sections of the original grant application.

Contributors All authors have made substantial contributions to the conception and design of this work. FB and MF led the development and writing of the original grant application. All authors collaborated to determine the processes for data collection, analysis and dissemination. All authors also reviewed and made critical comments on drafts of the original grant application. After the funding was awarded, FB, TDC and CM led the development, testing and refinement of the coding framework and associated data analysis processes, with intellectual input from MF, PH, DMcD and DM. TDC led the development of this manuscript with critical review provided by all other authors. All authors approved the final version of this manuscript and are prepared to take responsibility for the content. All authors also agree to be accountable for all aspects of the work and for ensuring that questions related to the accuracy or integrity of any part of the work are appropriately investigated and addressed.

Funding This work is supported by the Australian Research Council (ARC) (grant: DP160100244) between 2016 and 2019. This protocol was peer reviewed by the funding body prior to funding being awarded.

Disclaimer The ARC has no role in data collection, analysis or interpretation.

Competing interests None declared.

Patient consent Not required.

Ethics approval This research project has been approved by the Flinders University Social and Behavioural Research Ethics Committee (project number 7176).

Provenance and peer review Not commissioned; peer reviewed for ethical and funding approval prior to submission.

Open access This is an open access article distributed in accordance with the Creative Commons Attribution Non Commercial (CC BY-NC 4.0) license, which permits others to distribute, remix, adapt, build upon this work non-commercially, and license their derivative works on different terms, provided the original work is properly cited, appropriate credit is given, any changes made indicated, and the use is non-commercial. See: http:// creativecommons.org/licenses/by-nc/4.0/. 


\section{REFERENCES}

1. Commission on the Social Determinants of Health. Closing the gap in a generation: health equity through action on the social determinants of health. Geneva: World Health Organization, 2008.

2. Australian Institute of Health and Welfare. Australia's health 2014. Canberra: Australian Government, AlHW, 2014.

3. Australian Institute of Health and Welfare. Life expectancy. Canberra: Australian Institute of Health and Welfare, 2017.

4. Baum F. The new public health. 4th edn. Melbourne: Oxford University Press, 2015.

5. Australian Institute of Health and Welfare. Australia's health 2010 Canberra: Australian Government, Australian Institute of Health and Welfare, 2010.

6. Fisher M, Baum F, MacDougall C, et al. To what extent do Australian health policy documents address social determinants of health and health equity? J Soc Policy 2016;45:545-64.

7. Fisher M, Baum F, MacDougall C, et al. A qualitative methodological framework to assess uptake of evidence on social determinants of health in health policy. Evidence \& Policy: A Journal of Research, Debate and Practice 2015;11:491-507.

8. Fisher M, Baum F, MacDougall C, et al. Intersectoral action on $\mathrm{SDH}$ and equity in Australian health policy. Health Promot Int 2017;32:953-63.

9. Hetzel D, Page A, Glover J. Inequality in South Australia: key determinants of wellbeing. volume 1: the evidence. Adelaide: SA Department of Health, 2004.

10. Marmot M. Social determinants and the health of Indigenous Australians. Med J Aust 2011;194:512-3.

11. Marmot M, Allen J, Goldblatt P, et al. Fair society, healthy lives, the Marmot review, executive summary: Strategic review of health inequalities in England post-2010. London: U.K: Department of Health, 2010.

12. Marmot M, Friel S. Global health equity: evidence for action on the social determinants of health. J Epidemiol Community Health 2008;62:1095-7.

13. United Nations General Assembly. Political declaration of the highlevel Meeting of the General Assembly on the prevention and control of non-communicable diseases. New York: United Nations, 2012.

14. Australian Government. National Aboriginal and Torres Strait Islander Health Plan 2013-2023. Canberra: Commonwealth of Australia 2013.

15. Commonwealth Department of Health and Aged Care. The influences on mental health. Promotion, prevention and early intervention for mental health: a monograph. Canberra: Mental Health and Special Programs Branch: Commonwealth Department of Health and Aged Care, 2000

16. Whitehead M. The concepts and principles of equity and health. Int $J$ Health Serv 1992;22:429-45.

17. Brown L, Thurecht L, Nepal B. The cost of inaction on the social determinants of health. Canberra, ACT: NATSEM, 2012.

18. Kickbusch I, Buckett K, eds. Implementing health in all policies: Adelaide 2010. Adelaide: Department of Health, Government of South Australia, 2010.

19. Baum F, Fisher M, Lawless A. Australian experiences. In: Raphael $\mathrm{D}$, ed. Tackling health inequalities; lessons from international experiences. Toronto: Canadian Scholars Press, 2012.

20. Bryant T, Raphael D, Schrecker T, et al. Canada: a land of missed opportunity for addressing the social determinants of health. Health Policy 2011;101:44-58.

21. Newman L, Baum F, Harris E. Federal, state and territory governmen responses to health inequities and the social determinants of health in Australia. Health Promot J Austr 2006;17:217-25.

22. UCL Institute of Health Equity. Review of social determinants and the health divide in the WHO European Region: Final report. Copenhagen: World Health Organization Regional Office for Europe, 2013.

23. World Conference on Social Determinants of Health. Rio Political Declaration on Social Determinants of Health. Rio de Janeiro, Brazil: World Health Organization, 2011.

24. Senate Community Affairs Reference Committee. Australia's domestic response to the World Health Organisation's (WHO) Commissoin on Social Determinants of Health report "Closing the gap within a generation". Canberra: Commonwealth of Australia, 2013.

25. Fisher M, Baum F, MacDougall C, et al. Cross-sectoral action on SDH in Australian health policy: Are we getting there? Sydney: University of NSW, 2014.

26. Krieg AS. Aboriginal incarceration: health and social impacts. Med J Aust 2006;184:534-6.

27. Friel S G, ed. Improving urban health equity through action on the social and environmental determinants of health: Final Report of the GRNUHE. London: University College London, The Rockefeller Foundation, 2010.

28. Galvão LA, Edwards S, Corvalan C, et al. Climate change and social determinants of health: two interlinked agendas. Glob Health Promot 2009;(Suppl 1):81-4.

29. Australian Council of Trade Unions. Insecure work, anxious lives: the growing crisis of insecure work in Australia. Melbourne: ACTU, 2011.

30. McRae T, Webster P, Marinova D. Australia's low-carbon economy and Indigenous people. Transformations 2015;3:253-65.

31. Anderson I, Baum F, Bentley M, eds. Beyond bandaids: exploring the underlying social determinants of aboriginal health. Darwin: Cooperative Research Centre for Aboriginal Health, 2007. Papers from the Social Determinants of Aboriginal Health Workshop, Adelaide, July 2004

32. Campbell D, Burgess CP, Garnett ST, et al. Potential primary health care savings for chronic disease care associated with Australian Aboriginal involvement in land management. Health Policy 2011;99:83-9.

33. Osborne K, Baum F, Brown L. What works? A review of actions addressing the social and economic determinants of Indigenous health. Canberra: Australian Institute of Health and Welfare, Australian Insititute of Family Studies, 2013.

34. Justice Centre. The Council of State Governments: justice reinvestment in North Carolina: three years later. Washington DC: TCSG, 2014

35. Howard D, Quinn S, Blokland J, et al. Aboriginal hearing loss and the criminal justice system. Aboriginal Law Bulletin 1993;3.

36. Howlett M, Ramesh M, Perl A. Studying public policy: policy cycles and policy subsystems. Toronto: Oxford University Press, 2009.

37. Aronowitz S. Introduction. Horkheimer M, Critical theory: selected essays. New York: The Continuum Publishing Company, 2002.

38. Lather P. Critical inquiry in qualitative research: feminist and poststructural perspectives: science "After Truth". In: Kd M, Lapan $\mathrm{S}$, Foundations for research: methods of inquiry in education and the social sciences. New Jersey: Lawrence Erlbaum Publishers, 2004:203-15.

39. Crotty M. The foundations of social research: meaning and perspective in the research process. London: Sage, 1998.

40. Danermark B, Ekstrom M, Jakobsen L. Explaining society: critical realism in the social sciences. London: Routledge, 2002.

41. Miller C, Orchard L. Chapter 1: Towards a new progressive policy agenda. In: Miller C, Orchard L, eds. Australian public policy: progressive ideas in the neoliberal ascendency. Bristol: Policy Press, 2014:3-26.

42. Davis M. Chapter 2: Neoliberalism, the culture wars and public policy. In: Miller C, Orchard L, eds. Australian public policy: progressive ideas in the neoliberal ascendancy. Bristol: Policy Press, 2014:27-42.

43. Rose N. Governing "advanced" liberal democracies. The anthropology of the state: a reader, 1996:37-64.

44. Galvin R. Disturbing notions of chronic illness and individual responsibility: towards a genealogy of morals. Health 2002;6:107-37

45. Cockerham WC. Health lifestyle theory and the convergence of agency and structure. J Health Soc Behav 2005;46:51-67.

46. Tesh SN. Hidden arguments: Political ideology and disease prevention policy: Rutgers University Press, 1988.

47. Carter SM, Hooker LC, Davey HM. Writing social determinants into and out of cancer control: an assessment of policy practice. Soc Sci Med 2009;68:1448-55.

48. Fisher M, Baum F, MacDougall C, et al. Australian health policy and social determinants of health and equity: a review of policy content. Sydney: University of NSW, 2013.

49. Fisher M, Baum FE, MacDougall C, et al. To what extent do australian health policy documents address social determinants of health and health equity? J Soc Policy 2016;45:545-64.

50. Tesh S. Hidden arguments: political ideology and disease prevention policy. New Brunswick, NJ: Rutgers University Press, 1988.

51. Baum F, Fisher M. Why behavioural health promotion endures despite its failure to reduce health inequities. Sociol Health IIIn 2014;36:213-25

52. Hastings $\mathrm{G}$. Why corporate power is a public health priority. BMJ 2012;345:e5124.

53. Freudenberg N. Lethal but legal: corporations, consumption and protecting public health. New York: Oxford University Press, 2014.

54. Yin RK. Case study research: design and methods. London: Sage publications, 2013

55. Liamputtong P, Ezzy D. Qualitative research methods. 2nd edn. Melbourne, Australia: Oxford University Press, 2006.

56. Corbin J, A: S. Basics of qualitative research. California: Sage Publications, 2008. 
57. Bowen GA. Document analysis as a qualitative research method. Qualitative Research Journal 2009;9:27-40.

58. Bacchi C. Women, policy and politics: the construction of policy problems. London: Sage, 1999.

59. Bacchi C. Analysing policy: what's the problem represented to be? Pearson Education: Frenchs Forest, NSW, 2009.

60. Whitehead M. A typology of actions to tackle social inequalities in health. J Epidemiol Community Health 2007;61:473-8.

61. Sayer A. Realism and social science. London: Sage, 2000

62. Kingdon J. Agendas, alternatives and public policies. 2 edn. New York: Addison-Wesley Educational Publishers, 2011.

63. Lewis JM. Health Policy and Politics: Networks, Ideas and Power. Melbourne: IP Communications, 2005.

64. Hall PA. Policy paradigms, social learning, and the state: the case of economic policymaking in Britain. Comp Polit 1993;25:275-96.

65. Thelen K. Historical institutionalism in comparative politics. Annu Rev Polit Sci 1999;2:369-404.

66. National Congress of Australia's First Peoples. Submission on the National Aboriginal and Torres Strait Islander Health Plan. Canberra: NCAFP, 2013.

67. Leigh A. Battlers and billionaires: the story of inequality in Australia. Melbourne: Black Inc, 2013.
68. Whitehead M. Values, Policy, and Ecosystem Health Options for resolving the many ecological policy issues we face depend on the concept of ecosystem health, but ecosystem health is based on controversial, value-based assumptions that masquerade as science. Bio Science 2001;51:437-43.

69. Dahlgren G, Whitehead M. Policies and strategies to promote equity in health. Copenhagen: World Health Organization, Regional Office for Europe, 1992

70. Solar O, Irwin A. A conceptual framework for action on the social determinants of health: Social determinants of health discussion paper 2. Geneva: WHO, 2010.

71. Wilkinson RG, Marmot MG. Social determinants of health: the solid facts. Geneva: World Health Organization, 2003.

72. Carson B, Dunbar T, Chenhall RD, et al. Social determinants of Indigenous health: Allen \& Unwin, 2007.

73. USDH (US Department of Health Office of Disease Prevention), 2010. Healthy people 2020 https://www.healthypeople.gov/ (accessed on 16 Sep 2017).

74. Northridge ME, Sclar ED, Biswas P. Sorting out the connections between the built environment and health: a conceptual framework for navigating pathways and planning healthy cities. J Urban Health 2003;80:556-68. 